\title{
CAPS, ateliês e oficinas: artes no mundo, mundos na arte
}

\author{
Flávia de Macedo Cavallini (DD *
}

Universidade Federal do Espírito Santo, Vitória, ES, Brasil

Resumo

O artigo propõe-se a analisar de que maneira o encontro da arte com a clínica, sob o viés das oficinas, propostas durante a reforma psiquiátrica, pode constituir-se numa potência, em possibilidades de encontro, na medida em que se afasta de atitudes manicomiais que ainda fazem parte do percurso da saúde mental no Brasil. Pretende evidenciar, por conseguinte, a lógica da clínica ampliada e da redução de danos como bases da atenção psicossocial, tomando como partida o relato da própria experiência institucional enquanto artista plástica de um centro de atenção psicossocial para cuidados relacionados ao uso de álcool e outras drogas. Visibiliza, para este fim, o processo de criação audiovisual colaborativo construído e vivenciado pelos participantes das oficinas de artes, que é atravessado por questões relacionadas à saúde, doença, uso de drogas, redução de danos e liberdade; a produção artística coletiva é conduzida de maneira a ganhar uma dimensão ética e política, assim como o cuidado de si recebe um contorno estético que ultrapassa previsibilidades morais e punitivas.

Palavras-chaves: arte; oficinas; álcool e outras drogas.

\section{CAPS, ateliers and workshops: arts in the world, worlds in art}

\section{Abstract}

The article aims to analyze how the meeting of art and the clinic, under the bias of workshops, proposals for the reform of psychiatry, can constitute a power in possibilities of meeting, as it moves away from asylum attitudes that are still part of the mental health course in Brazil. It aims to highlight, therefore, the logic of expanded clinical and harm reduction as the basis of psychosocial care , taking as starting the account of own institutional experience as artist of a psychosocial care center for care related to alcohol and other drugs. For this purpose, it makes visible the process of the collaborative audiovisual creation, built and experienced by the participants of the art workshops, which is traversed by issues relate to health, illness, drug use, harm reduction and freedom; collective artistic production is conducted in such a way as to gain an ethical and political dimension, just a self-care receives an esthetical contour that goes beyond moral and punitive predictability.

Keywords: art; ateliers; alcohol and other drugs

\section{Produção coletiva de vídeo - cena final de O Sonho de Zé.}

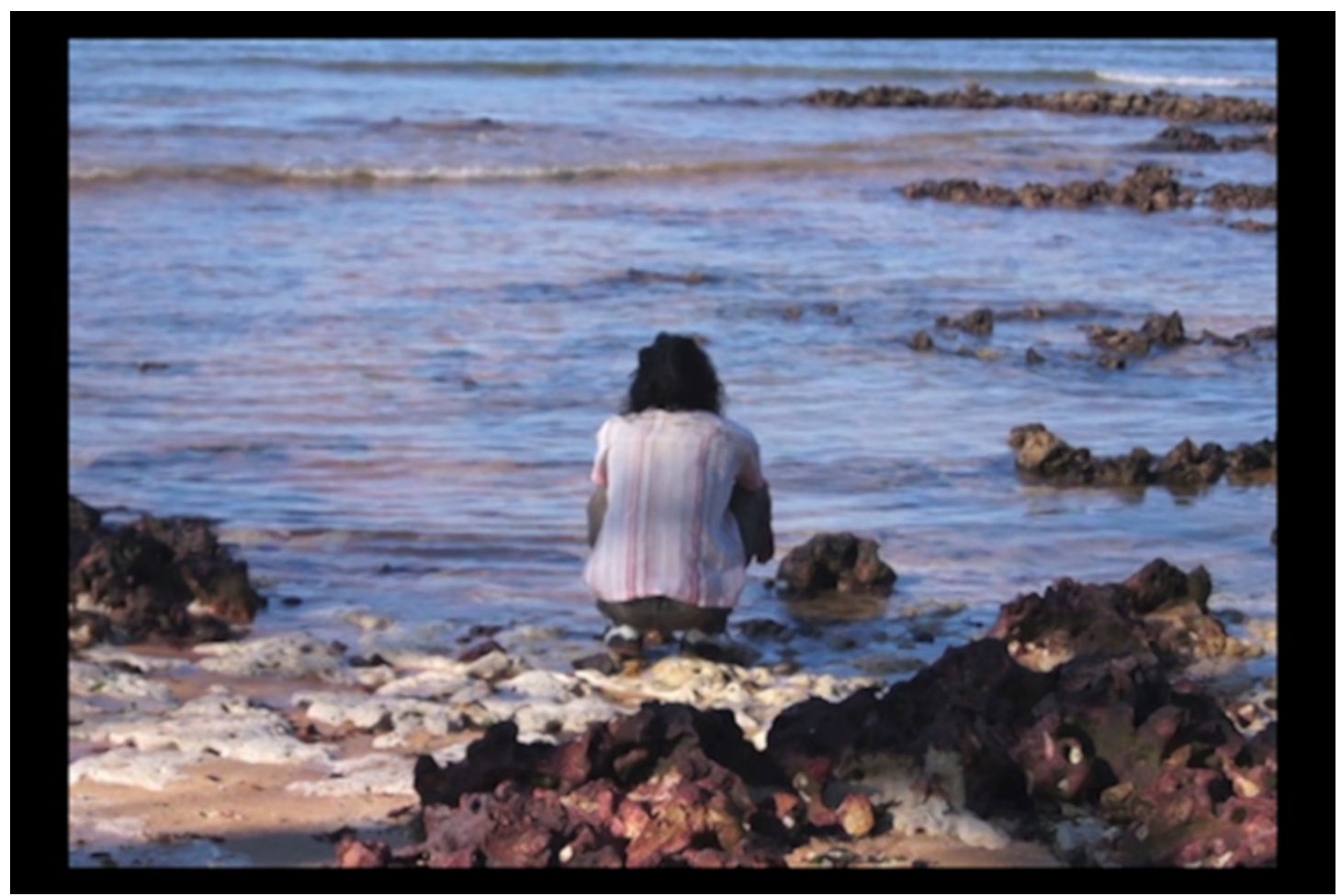

Fonte: registro do autor, Espírito Santo (2014).

\footnotetext{
^Endereço para correspondência: Universidade Federal do Espírito Santo. Av. Fernando Ferrari, 514 - Goiabeiras, Vitória - ES. CEP: 29075-910. E-mail: fla-

Os dados completos da autora encontram-se ao final do artigo.
} 
- Durante a aprendizagem sobre a erva do diabo, compreendi que ela não servia para mim, e não continuei mais no seu caminho.

— O que o levou a se decidir assim, Dom Juan?

- A erva do diabo quase me matava cada vez que eu tentava usá-la. Uma vez foi tão ruim que eu pensei que estava liquidado. No entanto, eu podia ter evitado todo esse sofrimento.

—Como? Há um meio especial de se evitar o sofrimento?

—Sim, há um meio.

—É uma fórmula, um processo, ou o quê?

— É um modo de agarrar as coisas. Por exemplo, quando eu estava aprendendo a respeito da erva do diabo, era por demais ansioso. Agarrava as coisas assim como as crianças agarram bala. A erva do diabo é apenas um entre um milhão de caminhos. Tudo é um entre um milhão de caminhos (CASTAÑEDA, 1976, p. 114).

Imaginemos uma situação fictícia, porém não menos real e corriqueira: um cidadão carinhosamente apelidado pelos amigos de Zé do Gole ${ }^{1}$ chega a um Centro de Atenção Psicossocial para cuidados relacionados ao uso abusivo de álcool e outras drogas - CAPS ad, ${ }^{2}$ num certo município do Espírito Santo; "sou dependente químico", "sou um adicto", "sou um drogado, preciso ser internado". Gravada na carne, linha dura, felizmente finita. Zé do Gole repete este bordão, segura-se a esta linha inúmeras vezes, dia após dia, até que algo acontece - ele vê outros caminhos, desenrola outros novelos. "É preciso", ele diz, "que dancemos de outra maneira, com cores, texturas, formas, manchas, cheiros... um pouco fortes, duros também no início, depois tudo vai ficando mais suave, mais e mais suave..." e quando esse pequeno grande momento de liberdade acontece, tão fugaz quanto o movimento do bailarino, enche-nos de alegria. Aí ele se foi... mas possivelmente outros virão.

A dificuldade de nosso protagonista é ter que caminhar ao lado da exacerbação da lógica da abstinência de uso de substâncias psicoativas, ${ }^{3}$ tendência que anda na contramão das conquistas da reforma psiquiátrica e da estratégia de redução de danos. ${ }^{4}$ Tal concepção de enfrentamento à dependência

${ }^{1}$ Zé do Gole é um nome fictício, criado pelos próprios usuários das oficinas de artes do CAPS ad.

${ }^{2}$ Os Centros de Atenção Psicossociais (CAPS) surgiram no contexto da reforma psiquiátrica no Brasil, a partir da década de 80 , como substitutivos aos aparatos manicomiais. Devem ser locais acolhedores e flexíveis, não burocratizados, com equipe interdisciplinar (médicos, psicólogos, farmacêuticos, assistentes sociais, enfermeiros, técnicos administrativos e de enfermagem, auxiliares de serviços gerais, artistas, músicos, educadores, entre outros), de base territorial, focados nas estratégias de Redução de Danos e da Clínica Ampliada.

${ }^{3}$ Em 2011 o Ministério da Saúde implantou o programa "Crack é possível vencer", tendo como principal pressuposto a ideia de que vivemos uma epidemia de crack. Sob esse entendimento, o recurso financeiro que poderia ser utilizado para implantação de novos centros de atenção psicossociais, ou fortalecimento da rede pública de saúde, passou a ser repartido com comunidades terapêticas e clínicas particulares, com a intenção de deter a suposta epidemia no Brasil "Para a execução do Plano Integrado de Enfrentamento ao Crack e outras Droga poderão ser firmados convênios, contratos de repasse, termos de cooperação, ajustes ou instrumentos congêneres com órgãos e entidades da administração pública federal, dos Estados, do Distrito Federal e dos Municípios, com consórcios públicos ou com entidades privadas" (Art. $7^{\circ}$-A do Decreto Lei $n^{\circ} 7.637$, de 8 de dezembro de 2011).

${ }^{4}$ Enquanto a Portaria $n^{\circ} 1.028 / \mathrm{GM}$, de $1^{\circ}$ de julho de 2005 , determina que as ações que visam à redução de danos sociais e à saúde, decorrentes do uso de produtos, substâncias ou drogas que causem dependência, sejam reguladas, a Portaria $\mathrm{n}^{0} 1.059 / \mathrm{GM}$, de 4 de julho de 2005, destina incentivo financeiro para o fomento de ações de redução de danos em Centros de Atenção Psicossocial para o Álcool e outras Drogas - CAPS ad. química vem favorecendo a produção de uma certa subjetividade, apropriando-se de aspectos cotidianos da vida das pessoas. Paulo Amarante (2014, p. 17) nos alerta que, apesar de terem sido criados, com a reforma psiquiátrica no Brasil, vários dispositivos de saúde mental, como CAPS, residências terapêuticas, projetos culturais e de economia solidária, é preciso que avancemos no sentido de também diminuir um discurso médico e farmacêutico sobre a existência:

Boa parte da chamada crise mundial de aumento da depressão é produzida pela Psiquiatria, que não está se preparando para evitar, mas para produzir depressão. Os relatórios contribuem para que as pessoas se identifiquem como depressivas. Os intelectuais orgânicos da indústria farmacêutica têm muito claro que é possível aumentar o número de diagnósticos de depressão ensinando a ser depressivo. "Você chora muito? Tem ideias de morrer?” Isso produz identificação e as pessoas não dizem que estão tristes e sim que estão depressivas. [Michel] Foucault ensinou que a pesquisa diagnóstica produz diagnóstico. É a produção social da doença.

Tentemos, então, junto com Zé do Gole, percorrer entornos poéticos, neste cotidiano entrelaçado de afetos, cores, cheiros, imagens e ruídos que tecem nossas redes. "A alegria [...], como o desejo, é uma estética da existência, do efêmero" (LINS, 2013, p. 265). Percursos que ao mesmo tempo nos desestabilizam e causam-nos vertigens; que nos ultrapassam mas que também nos acolhem. Qual o lugar do artista nestes acontecimentos? Félix Guattari (2012, p. 17) propõe que possamos ir ao encontro de uma "nova matéria de expressão", oferecendo possibilidades diversificadas de recomposição de uma corporeidade existencial, de saída das repetições incessantes, num sentido de ressingularização de subjetividades cristalizadas. Desta forma, a arte pode ser um caminho possível; assim como o autor, não nos referimos apenas à arte institucionalizada, que adentra os museus, galerias de arte e outros estabelecimentos sociais, culturais e mercadológicos, apesar de, muitas vezes, fazermos destes espaços institucionais lugares de encontros estéticos; a arte a que nos referimos aponta para o próprio processo de criação e sua implicação ética e política:

O novo paradigma estético tem implicações ético-políticas porque, quem fala em criação, fala em responsabilidade da instância criadora em relação à coisa criada, em inflexão de estado de coisas, em bifurcação para além de esquemas pré-estabelecidos e aqui, mais uma vez, em consideração do destino da alteridade em suas modalidades extremas (GUATTTARI, 2012, p. 123).

\section{Artes no mundo}

Uma das potências dos CAPS consiste, então, no cuidado transdisciplinar, presente, muitas vezes, em espaços chamados oficinas terapêuticas, que foram regulamentadas pela Portaria $n^{\circ} 189$ em 1991. Segundo esta Portaria, as oficinas são atividades grupais e possuem função de socialização, expressão e inserção social (BRASIL, 1991). A princípio não possuem distinção de profissionais, podendo ser coordenadas por um ou mais, mantendo a finalidade de "maior integração social e familiar, a realização de atividades produtivas e o exercício coletivo da cidadania" (BRASIL, 2004a, p. 20). 
As oficinas, diferentemente do que ocorria nos manicômios, não são práticas impostas àqueles que possuem transtornos mentais. São propostas de acordo com o projeto terapêutico formulado pela equipe terapêutica e é o usuário quem decide se as oficinas lhe interessam ou não. Há diversas modalidades de oficinas terapêuticas: oficinas expressivas, oficinas geradoras de renda e oficinas de alfabetização. As oficinas expressivas são espaços em que os usuários trabalham com a expressão plástica, como a pintura, por exemplo; a expressão corporal, como a dança; a expressão verbal, com poesias, contos etc.; a expressão musical; a fotografia; e o teatro. As oficinas geradoras de renda são para o sustento ou para complementação da renda daqueles que possuem intenso sofrimento psíquico, através da aprendizagem de alguma atividade específica. Podem ser de culinária, marcenaria, artesanato em geral, fabricação de velas, vendas etc. Assim, essas oficinas são importantes formas de promoção de autonomia e de reinserção social do sujeito. As oficinas de alfabetização são para aqueles que não tiveram acesso à educação formal ou não continuaram os estudos aprenderem a escrita e a leitura e, dessa forma, (re)construírem sua cidadania (BRASIL, 2004a).

Importante salientar que os dispositivos implantados por Osório César e Nise da Silveira, assim como seus seguidores, anos atrás — os ateliês livres de artes, diferentes das oficinas manicomiais — passaram a fazer parte da lógica psicossocial, inserida dessa maneira no funcionamento dos CAPS.

Voltemos ao Espírito Santo: quando iniciamos nosso trabalho no CAPS ad, percebíamos que as pessoas que lá chegavam não tinham a intenção inicial de produzir ou ao menos de conhecer arte. Isso de início dificultou a construção de um ateliê livre. Durante o ano de implantação do CAPS, não havia material nem carro para passeios, nem mesmo espaço adequado para a prática de algumas atividades. Mas havia um certo consenso entre os profissionais dos outros serviços de saúde mental que visitávamos, com o intuito de capacitação, em relação ao que os chamados "oficineiros" deveriam ou não fazer: não dar aulas, não conduzir demais as atividades, mas ao mesmo tempo prender a atenção dos usuários, ser interessantes.

Havia o receio, na época da implantação do serviço, de que o artista plástico direcionasse as oficinas para o ensino de técnicas artísticas em vez de facilitar a livre expressão de seus usuários. Por outro lado, a oficineira ouvia, para sua surpresa, o desejo das pessoas que frequentavam as oficinas "não diretivas":

- Tudo bem, a conversa tá boa, mas quando você vai nos ensinar alguma coisa? Você não é a artiiiista plássstica? falava, num claro tom de deboche misturado ao forte hálito etílico, dona Odete, ${ }^{5}$ uma das usuárias do serviço. Passaram então a chamar a oficineira de professora, rótulo que subsiste até hoje, talvez para reforçar um desejo de aprendizado:

- Poxa, professora, quando será nossa aula?

—Mas como assim, vocês querem aula? Eu não sou professora...

— Pra nós você é professora, pois vai nos ensinar alguma coisa.
—O que vocês pensaram?

- Você é quem sabe...

É preciso, então, que cada vez menos estejamos presos a modelos e mais voltados a exemplos, a aberturas, a fluxos de afetos e sensações.

Quando se deseja, por meio da arte ou do trabalho, produzir territórios existenciais (inserir ou reinserir socialmente os 'usuários', torná-los cidadãos...) cresse [sic] que está se falando (ao meu ver dever-se-ia falar) não de adaptação à ordem estabelecida, mas de fazer com que trabalho e arte se reconectem com o primado da criação, ou com o desejo ou com o plano de produção da vida. Pois que o plano de produção desejante é também o plano de engendramento do mundo humano (RAUTER, 2000, p. 271).

A oficineira em questão decidiu aceitar o personagem que lhe foi oferecido e atuar com o pouco material disponível para as oficinas, que era, na época, basicamente cola e papel. Oficinas de poesias, colagens, fanzines, fotonovelas, exibição de filmes, além de visitas a museus e galerias de arte surgiram neste ínterim. Aos poucos os usuários das oficinas de arte passaram a assumir mais o direcionamento das atividades que lhes interessavam; paralelamente o serviço foi conseguindo maior quantidade de materiais, como tintas, telas, pincéis, peças para mosaico, ferramentas para gravura, e a oficina foi ganhando ares de ateliê. Os usuários também se sentiram mais livres para improvisar e criar com materiais ligados ao seu próprio cotidiano; foi desta maneira que surgiu a primeira experiência audiovisual nas oficinas de arte.

\section{O Sonho de Zé: morte e vida severina num duelo de dominó}

Entre 2013 e 2014 iniciou-se, então, uma experiência coletiva de produção audiovisual de forma improvisada, com a câmera da oficineira e a iniciativa das pessoas envolvidas no regime intensivo do CAPS ad. O protagonismo dos usuários do estabelecimento na feitura e na condução da história, desde o desejo inicial de se "fazer um filme" até a edição compartilhada das cenas, possibilitou não apenas a expressão de pensamentos e sentimentos sobre a problemática do uso abusivo de substâncias psicoativas e sua condução pelas instâncias jurídicas e de saúde, mas também a vivência de possibilidades presentes na vida e que ganharam força no contato com a arte.

Produzir arte hoje é operar com vetores de um campo ampliado. Um campo que se abre ao entrecruzamento das diversas áreas do conhecimento, num panorama transdisciplinar, sem prejuízo de sua autonomia e especificidade enquanto prática da visualidade. A cultura como paisagem não natural configura o território onde se move o artista: sua ação transforma-se numa intervenção precisa ao mobilizar instabilidades do campo cultural (regiões da cultura que permitem problematizações, conflitos, paradoxos), por meio de uma inteligência plástica que torna visível uma rede de relações entre múltiplos pontos de oposições, onde o trabalho de arte é um dispositivo de processamento simultâneo e ininterrupto, e nunca uma representação destas relações (BASBAUM, 2013, p. 27). 
O fio condutor da narrativa do nosso vídeo foi a angústia do personagem Zé do Gole diante do uso exacerbado de álcool. Zé dorme e sonha; em seu sonho comparecem seus dilemas, seus anseios e seus temores. O julgamento social, o afastamento da poesia na vida, a fantasia da traição conjugal e a figura de seu falecido pai, como uma assombração, anunciando (ou desejando?) sua morte. Quase todas as cenas foram feitas em preto e branco, excetuando-se a cena final, por terem sido pensadas a partir de uma fotonovela em alto contraste que produzimos anos antes.

Num dado momento a questão da internação compulsória aparece, intempestivamente, na teatralidade do grupo, fato curioso, já que este assunto não fazia parte da fotonovela que servia como roteiro inicial. Nenhum dos participantes da oficina vivenciou esta experiência; porém, a ideia de um juiz que submete alguém a um tratamento de saúde como uma punição, e não como uma possibilidade libertadora, era algo que já vinha assombrando a imaginação de usuários do CAPS como um fantasma.

É possível tratar o mundo como sintoma, nele buscar os signos de doença, os signos de vida, de cura ou de saúde. E uma reação violenta é, talvez, a grande saúde que chega. Nietzsche considerava o filósofo como o médico da civilização. Henry Miller foi um diagnosticador prodigioso. $\mathrm{O}$ artista, em geral, deve tratar o mundo como um sintoma, e construir sua obra não como um terapeuta, mas, em todo caso, como um clínico. Não se fica fora dos sintomas, mas se faz com eles uma obra, que ora contribui para sua precipitação, ora para a sua transformação (DELEUZE, 2008, p. 181).

$\mathrm{O}$ processo que norteou a produção do nosso filme tem relação com uma prática contemporânea colaborativa que se faz a partir de uma autoria dispersa, num processo de contaminação que desafia a condução linear de uma narrativa. Há, consequentemente, uma dilatação espaço-temporal em que a intensificação e abertura de novos processos e meios são buscados em detrimento de regras e limites convencionados pelos sistemas de arte (WASEIM, 2008). Não se trata, no entanto, de práticas terapêuticas que transformam a arte numa ferramenta para a domesticação subjetiva, mas um processo que propicia criação de algo que faça emergir o intempestivo nas relações entre os participantes. O grupo aos poucos foi abandonando a ideia inicial de "correção" do comportamento de Zé (presente na fotonovela) e ampliando o diálogo acerca das questões políticas, institucionais e estéticas que compunham a existência do personagem.

\section{Arte como um jogo, potências que se afirmam}

Após assistir às filmagens que já haviam feito, a oficineira lembrou-se de um filme chamado O sétimo selo, ${ }^{6}$ em que o personagem Antonious, um cavaleiro do século XIV, faz um acordo com a Morte, desafiando-a para um duelo de xadrez. Relata ao grupo que a lembrança foi motivada pela conversa de Zé do Gole e o fantasma do pai, que lhe diz: "Zééééé....ô Zéééée...sou eu, seu pai...."- ao que Zé do Gole responde: - "Pai? Eu já sou avançado de idade, eu não respeito mais o senhor, o senhor tá morto!" -E recebe a notícia, assustado: "Eu sei... eu vim te bus${ }^{6}$ O SÉTIMO SELO. Direção: Ingmar Bergman, 1957, DVD (96 min), NTSC, $\mathrm{p} \& \mathrm{~b}$

Fractal, Rev. Psicol., v. 32 - n. 1, p. 40-45, 2020 car...". Como no filme de Bergman, o diálogo improvisado entre Zé do Gole e o seu pai-assombração aponta uma angústia e um temor diante do fim da vida. Angústia esta que comparece cotidianamente nos serviços de saúde e que, muitas vezes, se concretiza em derradeira realidade.

Assim que o grupo tem acesso à cena referida do filme de Bergman, alguém logo propõe: "E se Zé do Gole jogasse dominó com aquele que o assombra e o chama para a morte, como o cavaleiro que joga xadrez? Nossa realidade é a do dominó, que jogamos sempre depois do almoço". O protagonista, segundo uma outra pessoa do grupo, "deveria jogar de verdade a partida", de modo que no mínimo dois finais pudessem ser destinados ao personagem: um em que ele ganha a vida e outro em que perde para a morte. A criação da cena neste momento assume o caráter do próprio jogo, num contexto cotidiano. Zé do Gole enfrenta a morte em igualdade de condições, não mais num processo de vitimização, exclusão e culpa. Há, aqui, um desvio da moral da abstinência sugerida no início da trama para a proposta ética que se constrói a partir de agora.

Ética e moral não falariam de opostos, de contradições ou de polaridades e nem de idênticos, homogêneos e similares. Ao contrário, trata-se de vetores que expressariam em nossas vidas uma dimensão do visível — do já dado, do que se cristalizou - e uma dimensão invisível — das virtualidades, dos fluxos intempestivos que rompem o instituído. A ética não seria uma reprodução mas uma criação, não seria uma aplicação de regras preestabelecidas mas o uso de regras facultativas, um processo de pensamento e não a efetuação de soluções preconcebidas (MACHADO, 1999, p. 211).

A questão do jogo acabou se tornando central para uma virada na narrativa, no sentido de uma abertura: não se entregar à morte transformou-se numa maneira de estabelecer com ela uma negociação, de certa forma lúdica e ampla, em que o jogador em questão é quem faz o convite para o jogo, não aceita passivamente as regras de conduta, mas negocia, recria, ultrapassa as previsibilidades. Zé do Gole sai vencedor do seu embate, mas ressalva: "A morte está sempre à espreita, ela perdeu a batalha mas não perdeu a guerra. O Zé do Gole vai viver mais, mas um dia vai morrer, como todos nós. Faz parte da vida". Morrer é uma condição de todo ser humano, porém cuidar de si mesmo nos planos ético, estético e político traz para si e para o outro formas de promoção de uma liberdade, num viver potente (FOUCAULT, 2006). Não apenas adiar a morte, mas promover a vida em suas diferentes formas de expressão; não apenas suportar a vida, mas criá-la de diferentes maneiras, num fazer artístico.

Essa mesma potência, como afirmação da vida, aproxima-se do que Nietzsche nos diz a respeito de vida como obra de arte: ultrapassa regras morais e instituições sociais, mas que se molda, ética e esteticamente, de forma paulatina e transitória, "pois sempre de novo se abandona e é preciso abandonar" (NIETZSCHE, 2012, p. 259). O filósofo, então, sugere o que se deve aprender com os artistas:

De que meios dispomos para tornar as coisas mais belas, atraentes, desejáveis para nós, quando elas não o são? - e eu acho que em si elas nunca o são! Aí temos algo a apren- 
der com os médicos, quando eles, por exemplo, diluem o que é amargo ou acrescentam açúcar e vinho à mistura; ainda mais dos artistas, porém, que permanentemente se dedicam a tais invenções e artifícios. Afastarmo-nos das coisas até que não mais vejamos muita coisa delas e nosso olhar tenha de lhes juntar muita coisa para vê-la ainda — ou ver as coisas de soslaio e como que em recorte - ou dispô-las de forma tal que elas encubram parcialmente umas às outras e permitam somente vislumbres em perspectivas - ou contemplá-las por um vidro colorido ou à luz do poente ou dotá-las de pele e superfície que não seja transparente: tudo isso devemos aprender com os artistas, e no restante ser mais sábios do que eles. Pois neles esta sutil capacidade termina, normalmente, onde termina a arte e começa a vida; nós, no entanto, queremos ser os poetas-autores de nossas vidas, principiando pelas coisas mínimas e cotidianas (NIETZSCHE, 2012, p. 179).

\section{Mundos na arte}

Surgiram muitas definições para arte e para a beleza durante a feitura do nosso pequeno filme: "a beleza é aquilo que te faz sentir bem"; "beleza é aquilo que agrada e comunica de alguma forma"; "se esse objeto feio for feito por um artista, aí é belo"; "a dedicação do artista torna a obra bela"; "a feitura da obra traz um valor, um prestígio, uma memória, um exemplo, um incentivo"; "uma bela arte depende de um aperfeiçoamento", até: "a arte não segue um padrão; depende da intenção do artista", "devemos extrair beleza daquilo que nos rodeia" e "o erro faz parte do artista e da arte" (a beleza do erro! A arte da vida cotidiana!).

Artesãos descobriram a pintura abstrata, senhores aposentados apaixonaram-se por artistas contemporâneos, jovens descobriram o gosto pelo figurativismo e técnicas de estamparia em camisetas, alguns se interessaram por vídeos, teatro e performance, outros ainda passaram a valorizar suas próprias vivências estéticas, como catadores de materiais recicláveis, bordadeiros, cabeleireiros, manicures, ressignificando-as e ao mesmo tempo discutindo questões sociais de valorização e desvalorização de alguns discursos disciplinares.

Tempo, espaço, normalidade, anormalidade, sobriedade, música, drogas, embriaguez, sexualidade, alegria, doença, vida e morte atravessaram e ainda atravessam nossas vivências não apenas durante as oficinas, mas principalmente nas visitas a galerias, museus e outros espaços públicos ligados à arte, ao artesanato, nos espaços de luta política, manifestações em praças públicas, inserção de usuários e profissionais em conselhos e movimentos ligados à pessoa com deficiência, conselho local de saúde, conselho de cultura, entre outros. Mundos que nasceram no encontro com a arte, que por sua vez tornou-se múltipla em seus inúmeros colóquios com o mundo.

\section{Informações sobre a autora:}

\section{Flávia de Macedo Cavallini}

\section{iD https://orcid.org/0000-0003-2394-6870}

(9) http://lattes.cnpq.br/8999985817021848

Artista plástica, com graduação em Artes Plásticas e Psicologia (UFES), mestra em Psicologia Institucional pela Universidade Federal do Espírito Santo (UFES). Atua de forma interdisciplinar no campo da arte moderna e contemporânea assim como na área de psicologia. Participa de diversas exposições, dentro e fora do país. Principais linguagens utilizadas: pintura, desenho, artes gráficas e fotografia.

\section{Como citar este artigo:}

\section{ABNT}

CAVALLINI, Flávia de Macedo. CAPS, ateliês e oficinas: artes no mundo, mundos na arte. Fractal: Revista de Psicologia, Niterói, v. 32, n. 1, p. 40-45, jan./abr. 2020. https://doi.org/10.22409/19840292/v32i1/5671

\section{APA}

Cavallini, F. M.. (2020, Janeiro/Abril). CAPS, ateliês e oficinas: artes no mundo, mundos na arte. Fractal: Revista de Psicologia, 32(1), 40-45. doi: https://doi.org/10.22409/1984-0292/v32i1/5671

\section{Referências}

AMARANTE, Paulo. Saúde mental e atenção psicossocial. Rio de Janeiro: Fiocruz, 2007.

AMARANTE, Paulo. Queremos diminuir a apropriação que a medicina faz da vida cotidiana. RADIS - Fiocruz, Rio de Janeiro, n. 146, p. 14-17, nov./2014. Disponível em: https:// radis.ensp.fiocruz.br/phocadownload/revista/Radis146_web. pdf. Acesso em: 12 out. 2018.

BASBAUM, Ricardo. Manual do artista-etc. Rio de Janeiro: Azougue, 2013.

Brasil. Ministério da Saúde. Secretaria Nacional de Assistência à Saúde. Portaria $n^{\circ} 189$, de 19 de novembro de 1991. Aprova a inclusão de grupos e procedimentos da tabela do SIH-SUS, na área de saúde mental (Hospitais Psiquiátricos). Brasília: MS, 1991.

BRASIL. Lei $n^{\circ} 10.216$, de 6 de abril de 2001. Dispõe sobre a proteção e os direitos das pessoas portadoras de transtornos mentais e redireciona o modelo assistencial em Saúde Mental. Brasília, MS: 2001.

BRASIL. Ministério da Saúde. Portaria $n^{\circ} 336$, de 19 de fevereiro de 2002. Estabelece que os Centros de Atenção Psicossocial poderão constituir-se nas seguintes modalidades de serviços: CAPS I, CAPS II e CAPS III, definidos por ordem crescente de porte/complexidade e abrangência populacional. Brasília, MS: 2002

BRASIL. Ministério da Saúde. Secretaria de Atenção à Saúde. Departamento de Ações Programáticas Estratégicas. Saúde mental no SUS: os centros de atenção psicossocial. Brasília, MS: 2004a.

BRASIL. Ministério da Saúde. Secretaria de Atenção à Saúde. SVS/CN-DST/AIDS. A Política do Ministério da Saúde para Atenção Integral a Usuários de Álcool e outras Drogas. 2. ed. Brasília, MS: 2004b.

BRASIL. Ministério da Saúde. Secretaria de Atenção à Saúde. Núcleo Técnico da Política Nacional de Humanização. Clínica ampliada, equipe de referência e projeto terapêutico singular. 2. ed. Brasília, MS: 2008. 
BRASIL. Decreto-Lei $n^{\circ}$ 7.637, de 11 de dezembro de 2011. Altera o Decreto $\mathrm{n}^{\mathrm{0}} 7.179$, de 20 de maio de 2010, que institui o Plano Integrado de Enfrentamento ao Crack e outras Drogas. Disponível em: http:/www.planalto.gov.br/ccivil 03/ Ato2011-2014/2011/Decreto/D7637.htm. Acesso em: 20 fev. 2015.

Brasil. Ministério da Saúde. Portaria $n^{\circ} 854$, de 22 de agosto de 2012. Altera a Tabela de Procedimentos, Medicamentos, Órteses, Próteses e Materiais Especiais do Sistema Único de Saúde. Disponível em: http://bvsms.saude.gov.br/bvs/ saudelegis/sas/2012/prt0854 2208 2012.html. Acesso em: 20 fev. 2015

CASTAÑEDA Carlos. A Erva do Diabo, 2. ed. São Paulo: Edibolso, 1976.

DELEUZE, Gilles. A ilha deserta. São Paulo: Iluminuras, 2008.

FOUCAULT, Michel. A Hermenêutica do sujeito. 2 ed. São Paulo: Martins Fontes, 2006.

GUATTARI, Félix. Caosmose: um novo paradigma estético. 2. ed. Rio de Janeiro: Ed. 34, 2012.

LINS, Daniel. O último copo: álcool, literatura, poesia. Rio de Janeiro: Civilização Brasileira: 2013.

MACHADO, Leila Domingues. Ética. In: BARROS, Maria Elizabeth Barros (Org). Psicologia: questões contemporâneas. Vitória: Edufes, 1999. p. 211-229.

NIETZSCHE. Friedrich. A gaia ciência. São Paulo: Companhia das Letras, 2012.

O SÉTIMO SELO. Direção de Ingmar Bergman, 1957, DVD (96 min), NTSC, p\&b.

RAUTER, Cristina. Oficinas para quê? Uma proposta éticoestético-política para oficinas terapêuticas. In: AMARANTE, P. (Org.). Ensaios: Subjetividade, saúde mental, sociedade. Rio de Janeiro: Fiocruz, 2000. p. 267-277.

WASEIM, Marcelo Simon. Processos colaborativos, contaminações e jogos de alteridade em arte pública: experiências na criação de uma rádio comunitária. 2008. Dissertação (Mestrado) - Programa de Pós-Graduação em Artes Visuais - Universidade do Estado de Santa Catarina, Florianópolis, Santa Catarina, 2008. 